\title{
Implementasi Media Video Pembelajaran Pendidikan Lingkungan Hidup Terintegrasi IPA untuk Siswa Sekolah Dasar pada Platform Youtube
}

\author{
Mohammad Fahmi Nugraha ${ }^{1,2}$, Ahman Sya ${ }^{1}$, Sunaryo' ${ }^{1}$, Achmad Husen ${ }^{1}$, Budi \\ Hendrawan $^{2}$, Agung Purwanto ${ }^{1}$ \\ ${ }^{1}$ Universitas Negeri Jakarta, ${ }^{2}$ Universitas Muhammadiyah Tasikmalaya \\ ${ }^{1} J$ l. Rawamangun Muka, RT.11/RW.14, Rawamangun, Pulo Gadung, Kota Jakarta Timur, \\ Daerah Khusus Ibukota Jakarta 13220 \\ ${ }^{2} J$ J. Tamansari KM. 2,5 Kota Tasikmalaya 46196
}

Correspondence Email: m.fahminugraha@umtas.ac.id

\begin{abstract}
This study aims to find out how to implement the Integrated Science Environmental Education Learning Video Media for Elementary School Students on the Youtube Platform. The method used is a qualitative research method with descriptive analysis techniques with library research by examining the implementation of science-integrated environmental education learning video media for elementary school students on the youtube platform. Data collection is done by reducing documents in the form of reports, news and research articles both nationally and internationally related to the topic of this research article. The results of the study indicate that the use of integrated science environmental education learning video media uploaded to youtube can make it easier for teachers and students to find materials related to the material presented. In addition to listening to learning videos, the use of the YouTube platform as a learning medium can be an educational medium for children where in its use children are taught how to use technology properly as a support for their learning.
\end{abstract}

\section{Keywords}

Learning Video Media, Environmental Education, Science, Elementary School, Youtube Platform

\begin{abstract}
Abstrak
Penelitian ini bertujuan untuk mengetahui bagaimana implementasi Media Video Pembelajaran Pendidikan Lingkungan Hidup Terintegrasi IPA untuk Siswa Sekolah Dasar pada Platform Youtube. Metode yang digunakan merupakan metode penelitian kualitatif dengan teknik analisis deskriptif dengan kajian kepustakaan (library research) dengan mengkaji implementasi media video pembelajaran pendidikan lingkungan hidup terintegrasi IPA untuk siswa sekolah dasar pada platform youtube. Pengumpulan data dilakukan dengan cara mereduksi dokumen berupa laporan-laporan, berita-berita serta artikel-artikel penelitian baik nasional maupun internasional yang berkaitan dengan topik artikel penelitian ini. Hasil penelitian menunjukkan bahwa penggunaan media video pembelajaran pendidikan lingkungan terintegrasi IPA yang diunggah ke youtube dapat memudahkan guru dan siswa dalam mencari bahan terkait materi yang disampaikan. Selain menyimak video pembelajaran, penggunaan platform youtube sebagai media pembelajaran dapat menjadi media edukasi untuk anak dimana dalam penggunaannya anak diajarkan cara menggunakan teknologi dengan baik sebagai penunjang untuk belajarnya.
\end{abstract}

\section{Kata Kunci}

Media Video Pembelajaran, Pendidikan Lingkungan Hidup, IPA, Sekolah Dasar, Platform Youtube

\section{A. PENDAHULUAN}

Media video termasuk suatu media audio visual, Visualization through learning media is one way that can be done to concretize something abstract (Pratiwi et al., 2019). Pada 
awalnya media sebagai alat peraga, kemudian dikenal dengan istilah Audio Visual Aids (alat bantu pandang/dengar), media juga disebut sebagai instructional materials (materi pembelajaran) dan kini istilah yang lazim digunakan dalam dunia pendidikan nasional adalah instructional media (media pendidikan atau media pembelajaran) (Nugraha et al., 2020). Dalam perkembangan teknologi saat ini, guru dimudahkan dengan banyaknya sumber referensi tentang strategi, metode, model dan media pembelajaran yang tersedia di jaringan internet, sejalan dengan hal itu tren yang saat ini terjadi adalah pembelajaran yang berpusat pada siswa (student centered), menindaklanjuti hal tersebut, peran video pembelajaran praktikum IPA sederhana sangat medukung terlaksananya pembelajaran yang berpusat pada siswa.

Pendidikan lingkungan hidup lahir dari permasalahan-permasalahan lingkungan, dimulai pada tahun 1972 melalui konferensi stockholm yang dilaksanakan di Stockholm Swedia pada tanggal 5-16 Juni yang saat ini tanggal tersebut kita kenal dengan hari lingkungan hidup sedunia, hasil dari konferensi stockholm adalah terbentuknya United Nations Environment Programme (UNEP) selain terbentuk badan/lembaga di bidang lingkungan, konferensi tersebut juga menghasilkan beberapa prinsip dalam pengelolaan lingkungan salah satu prinsipnya adalah bahwa pendidikan lingkungan dianggap sangat penting sehingga ditindaklanjuti pada lokakarya internasional yang dilakukan di Kota Belgrade Yugoslavia, PLH dicetuskan melalui keputusan bersama antar peserta lokakarya, pernyataan tersebut dikenal dengan The Belgrade Charter - a Global Framework for Environmental
Education, adapun secara rinci pernyataan tersebut menghasilkan prinsip dalam pendidikan lingkungan yaitu:

1. Environmental education should consider the environment in its totality I natural and man-made, ecological, political, economic, technological, social, legislative, cultural and esthetic.

2. Environmental education should be a continuous life-long process, both inschool and out-of-school.

3. Environmental education should be interdisciplinary in its approach.

4. Environmental education should emphasise active participation in preventing and solving environmental problems.

5. Environmental education should examine major environmental issues from a world point of view, while paying due regard to regional differences.

6. Environmental education should focus on current and future environmental situations.

7. Environmental education should examine all development and growth from an environmental perspective.

8. Environmental education should promote the value and necessity of local, national and international cooperation in the solution of environmental problems. (UnescoUnep, 1976)

Secara ringkas tujuan PLH yang dirumuskan dalam Belgrade Charter tersebut adalah:

1. Meningkatkan kesadaran dan perhatian terhadap keterkaitan bidang ekonomi, sosial, politik serta ekologi, baik di daerah perkotaan maupun pedesaan;

2. Memberi kesempatan bagi setiap orang untuk mendapatkan pengetahuan, keterampilan, 
sikap/perilaku, motivasi dan komitmen, yang diperlukan untuk bekerja secara individu dan kolektif untuk menyelesaikan masalah lingkungan saat ini dan mencegah munculnya masalah baru;

3. Menciptakan satu kesatuan pola tingkah laku baru bagi individu, kelompok-kelompok dan masyarakat terhadap lingkungan hidup. (Sudjoko, 2014)

Prinsip-prinsip dalam PLH diatas kemudian disebarluaskan dan mulai diterapkan oleh negara-negara dengan harapan hadirnya PLH dapat menjadi jawaban atas segala permasalahan-permasalahan

lingkungan yang ada. Di Indonesia perkembangan penyelenggaraan pendidikan lingkungan dimulai pada tahun 1975. IKIP Jakarta (sekarang Universitas negeri Jakarta - UNJ) untuk pertama kalinya merintis pengembangan pendidikan lingkungan dengan menyusun Garisgaris Besar Program Pengajaran PLH yang diujicobakan di 15 Sekolah Dasar di Jakarta pada periode tahun 1977/1978. Pada tahun 1979 dibentuk Pusat Studi Lingkungan (PSL) di berbagai perguruan tinggi negeri dan swasta. Bersamaan dengan itu pula mulai dikembangkannya pendidikan Analisis Dampak Lingkungan (ANDAL, kini Analisis Mengenai Dampak Lingkungan = AMDAL) oleh semua PSL di bawah koordinasi Menteri Negara Pengawasan Pembangunan dan Lingkungan Hidup (Meneg-PPLH). Saat ini jumlah PSL yang menjadi anggota BKPSL telah berkembang menjadi 87 PSL. Di samping itu berbagai perguruan tinggi baik negeri maupun swasta mulai mengembangkan dan membentuk program studi khusus ilmu lingkungan dan pendidikan lingkungan. Sebagai pelopor program studi ilmu lingkungan adalah IPB Bogor dan UI Jakarta, sedangkan program studi PKLH adalah IKIP Jakarta. Pada jenjang pendidikan dasar dan menengah (menengah umum dan kejuruan), penyampaian masalah kependudukan dan lingkungan hidup secara integratif dituangkan dalam sistem kurikulum tahun 1984 dengan memasukkan masalah-masalah kependudukan dan lingkungan hidup ke dalam hampir semua mata pelajaran. Sejak tahun 1989/1990 hingga saat ini berbagai pelatihan tentang lingkungan hidup telah diperkenalkan oleh Departemen Pendidikan Nasional bagi guru-guru SD, SMP, dan SMA termasuk Sekolah Kejuruan. Prakarsa pengembangan pendidikan lingkungan juga dilakukan oleh berbagai LSM. Pada tahun 1996/1997 terbentuk Jaringan Pendidikan Lingkungan (JPL) antara LSM-LSM yang berminat dan menaruh perhatian terhadap pendidikan lingkungan. Hingga tahun 2001 tercatat 76 anggota JPL yang bergerak dalam pengembangan dan pelaksanaan pendidikan lingkungan (Surakusumah, 2009).

Pendidikan lingkungan bersifat multidisiplin sehingga dalam pelaksanaannya sangat mungkin untuk diintegrasikan ke dalam semua mata pelajaran, begitupun dengan proses pembelajarannya, pendidikan lingkungan hidup mengajarkan siswa untuk lebih dekat dengan lingkungannya sehingga pembelajaran dapat dilakukan dengan menyenangkan. Proses belajar mengajar sebaiknya dilakukan dengan pendekatan lingkungan. Dasar filosofis mengajar dengan mengimplementasikan 
pendekatan lingkungan alam sekitar adalah dari Rousseau dan Pestalozzi. Rousseau mengatakan bahwa kesadaran dan aktifitas fisik adalah faktor utama dalam pendidikan anak-anak. Rousseau percaya bahwa "anak harus belajar langsung dari pengalaman sendiri daripada harus mendengarkan dari penjelasan buku". Disini lingkungan sangat berperan penting dalam proses pembelajaran. Sedangkan Johan Heinrich Pestalozi (1716-1827), seorang pendidik berkebangsaan Swiss dengan konsep Home Schoolnya menjadikan lingkungan alam sekitar sebagai objek nyata untuk memberikan pengalaman pertama bagi anak-anak. Pestalozzi juga mengajarkan ilmu bumi dan alam sekitar kepada anak didiknya dengan fasilitas yang ada dilingkungan sekitarnya dan menanamkan rasa tanggung jawab pada diri anak akan dirinya sendiri juga lingkungan agar tetap seimbang (Suko Pratomo, Asep Saefurokhman, 2010).

Pendidikan lingkungan hidup pada prinsipnya melibatkan tiga organ tubuh manusia yaitu otak untuk menerima pengetahuan, hati untuk menerapkan nilai-nilai dalam pendidikan lingkungan serta tangan untuk mulai bergerak dan membiasakan diri untuk berperilaku cinta lingkungan. Berdasarkan definisi, pendidikan lingkungan merupakan suatu proses yang bertujuan membentuk perilaku, nilai dan kebiasaan untuk menghargai lingkungan hidup. Dengan definisi diatas kita dapat menyimpulkan bahwa pendidikan lingkungan hidup harus diberikan sejak dini kepada anak-anak kita, dan yang paling penting pendidikan lingkungan hidup harus berdasarkan pengalaman langsung bersentuhan dengan lingkungan hidup sehingga diharapkan pengalaman langsung tersebut dapat membentuk perilaku, nilai dan kebiasaan untuk menghargai lingkungan (Surakusumah, 2009).

Tujuan pembelajaran IPA untuk tingkat sekolah dasar adalah: (1) Memperoleh keyakinan pada kebesaran Tuhan Yang Maha Esa berdasarkan keberadaan, keindahan dan keteraturan alam ciptaanya. (2) mengembangkan pengetahuan konsep-konsep IPA yang bermanfaat dan dapat diterapkan dalam kehidupan sehari-hari. (3) mengembangkan rasa ingin tahu, sikap positif dan kesadaran tentang adanya hubungan yang saling mempengaruhi antar IPA, lingkungan, teknologi dan masyarakat. (4) mengembangkan keterampilan proses untuk menyelidiki alam sekitar memecahkan masalah dan membuat keputusan. (5) meningkatkan kesadaran untuk berperan serta dalam memelihara. (6) menjaga dan melestarikan lingkungan alam dan segala keteraturanya sebagai salah satu ciptaan Tuhan. (7) memperoleh bekal pengetahuan, konsep dan keterampilan IPA sebagi dasar untuk melanjutkan pendidikan (Rini et al., 2014).

Berdasarkan tujuan pembelajaran IPA diatas dapat dikatakan bahwa IPA bukan hanya berbicara tentang teori saja, namun IPA juga melibatkan seluruh anggota tubuh siswa dalam hal mengembangkan keterampilan proses untuk menyelidiki alam sekitar, memecahkan masalah dan membuat keputusan, dengan 
demikian tujuan yang terakhir dari proses pembelajaran IPA yaitu memperoleh bekal pengetahuan, konsep dan keterampilan IPA sebagi dasar untuk melanjutkan pendidikan dapat dicapai dengan maksimal, dengan demikian hasil belajar yang diharapkan dari pembelajaran IPA bukan hanya dari aspek pengetahuan saja, namun juga pada aspek keterampilan dan sikap.

Guru IPA di sekolah dasar selain menguasai materi tentunya juga harus mampu mengarahkan siswanya mencapai hasil belajar dengan maksimal, hal tersebut mampu tercapai salah satunya dengan penggunaan media pembelajaran yang melibatkan siswa langsung ke dalam penyampaian materi sehingga proses pembelajaran menjadi mudah dan menyenangkan bagi siswa.

Big data merupakan sekumpulan data dalam jumlah besar yang dapat digunakan oleh pengumpul data untuk mencapai tujuan mereka, contohnya adalah pada perusahaan sosial media baik itu berbasis pesan singkat maupun sosial media lainnya, perusahaan tersebut akan memiliki data dari para penggunanya, contohnya adalah facebook, saat kita mengisi data diri, secara otomatis data yang kita isi akan masuk ke big data perusahaan tersebut sehingga kerahasiaan/privacy kita juga menjadi milik mereka, lantas data tersebut digunakan untuk mempromosikan iklan-iklan dari perusahaan/toko yang sudah bekerjasama dengan perusahaan sosial media tersebut (Almahendra, 2018). Big data dimulai pada tahun 2005 oleh Roger Magoulas, peran big data dalam dunia bisnis sangat bermanfaat, big data dapat digunakan untuk membaca karakteristik dan kecenderungan minat konsumennya, contohnya adalah ketika kita sedang berbelanja di aplikasi online akan ada banyak barang-barang yang direkomendasikan aplikasi tersebut, hal tersebut dilakukan dengan membaca sejarah pencarian kita terkait barang yang kita cari pada aplikasi tersebut, selain untuk membaca karakteristik konsumen, big data juga digunakan untuk menentukan marketing strategy yaitu penentuan langkah dan strategi dalam menjangkau setiap segmen pasar sehingga konsumen dengan karakteristik yang tidak terbatas dapat disentuh dengan berbagai marketing strategy yang dipilih berdasarkan big data yang terkumpul (Nilakusmawati, 2019).

Salah satu penerapan big data dalam dunia pendidikan adalah aplikasi big data dalam pemetaan pendidikan di Kalimantan Barat berbasis geospasial adalah sebuah aplikasi yang memungkinkan para penggunanya untuk mengakses data pendidikan, data ini diambil berdasarkan aspek keruangan yang menunjukkan lokasi, letak, dan posisi suatu objek atau kejadian yang berada di bawah, pada, atau di atas permukaan bumi yang dinyatakan dalam sistem koordinat tertentu, data ini disajikan dalam berbagai bentuk tampilan, mulai dari profil sekolah, jumlah siswa, guru, staff, hingga lokasi dan street view dari setiap sekolah yang diinput dalam aplikasi tersebut karena sudah terintegrasi dengan google maps, kondisi ini sangat memungkinkan para orangtua, guru, pengawas dan pihak lainnya yang berkepentingan 
untuk mengakses laman tersebut untuk melakukan monitoring dan evaluasi pelaksanaan pendidikan di wilayah Kalimantan Barat (Barat, 2020).

Youtube merupakan sebuah platform untuk memublikasikan video, platform ini dapat diakses oleh semua orang di negara manapun. Platform ini resmi berdiri pada tahun 2005. Pendirinya adalah Chad Hurley, Steve Chen, Jawed Karim dimana mereka bertiga adalah mantan karyawan PayPal. Kemudian platform Youtube dibeli oleh Google dan diperkenalkan kembali pada tahun 2006. Berdasarkan riset yang dilakukan oleh hootsuite sangat jelas bahwa Youtube sangat digemari oleh masyarakat Indonesia, dengan menduduki most active social media (Putra \& Patmaningrum, 2018).

\section{B. HASIL DAN PEMBAHASAN 1. HASIL}

Keberhasilan pelaksanaan PLH ditentukan oleh kejelasan tujuan atau sasaran yang hendak dicapai. Secara umum tujuan pendidikan kependudukan dan lingkungan hidup adalah membina dan mengembangkan anak didik agar memiliki sikap dan tingkah laku kependudukan serta dapat mengelola lingkungan hidup secara rasional dan bertanggung jawab dalam rangka memelihara keseimbangan sistem lingkungan dan penggunaan sumber daya alam secara spritual maupun material. Pembelajaran pendidikan lingkungan hidup saat ini sudah diintegrasikan ke dalam seluruh mata pelajaran yang ada sehingga diperlukan kemampuan guru dalam merencanakan, mempersiapkan, melaksanakan hingga mengevaluasi proses pembelajaran tersebut.
Seiring dengan perkembangan jaman dan teknologi saat ini, banyak sekali ditemukan inovasi yang dapat menunjang proses pembelajaran pendidikan lingkungan, salah satunya adalah dengan menggunakan video pembelajaran yang diunggah di platform youtube sehingga video pembelajaran dapat diakses oleh siapapun yang membutuhkannya, keberadaan dan penggunaan media pembelajaran yang bervariatif diharapkan dapat menjadi solusi untuk kesuksesan pembelajaran di sekolah dasar salah satunya adalah penggunaan media video pembelajaran pendidikan lingkungan terintegrasi IPA yang diunggah ke youtube, hal tersebut dapat memudahkan guru dan siswa dalam mencari bahan terkait materi yang disampaikan.

\section{PEMBAHASAN}

Tujuan pendidikan lingkungan hidup pada prinsipnya adalah untuk menciptakan manusia yang humanis dan mencintai lingkungannya, untuk mencapai kondisi ideal tersebut nilainilai pendidikan lingkungan harus ditanamkan sejak dini baik pada jenjang pendidikan pra-sekolah (PAUD dan TK) maupun pada jenjang pendidikan sekolah dasar, pada kurikulum 2004, mata pelajaran pendidikan lingkungan hidup sudah dilakukan secara terpadu (integratif).

Kurikulum 2013 di sekolah dasar sudah menggunakan pendekatan tematik terpadu dengan ciri khasnya batas antar setiap mata pelajaran tidak terlihat jelas namun pelajaran dilakukan dalam bentuk tema, implementasi pendidikan lingkungan pada kurikulum 2013 diintegrasikan pada setiap mata pelajaran sehingga para pendidik harus memiliki kompetensi tambahan juga berkaitan dengan pendidikan 
lingkungan, mindset pendidikan lingkungan saat ini khususnya pada sekolah-sekolah dasar di daerah adalah hanya sebatas melakukan program bersih-bersih meskipun kegiatan tersebut termasuk ke dalam aplikasi sikap dalam tujuan pembelajaran pendidikan lingkungan hidup namun ada materi-materi dan isu-isu terkini terkait dengan pendidikan lingkungan yang haris diberikan kepada siswa, seperti pemanasan global (global warming), pendinginan global (global diming), climate change (perubahan iklim), carryng capacity dan isu-isu terkini lainnya terkait pendidikan lingkungan hidup.

Pemilihan pendekatan terpadu terhadap PLH yang berarti memperlakukan PLH sebagai bagian yang dipadukan dengan mata pelajaran yang lain akan membawa pengaruh yang wajar terhadap program kurikulum, antara lain yang menyangkut tenaga pengajar. Tenaga pengajar akan lebih mudah diperoleh, karena tenaga pengajar PLH adalah guru-guru mata pelajaran atau guru kelas yang memegang mata pelajaran sebagai wadah perpaduan itu sendiri. Dengan demikian pendekatan terpadu akan lebih mempermudah dan memperlancar pelaksanan PLH, makin baik karena makin banyak yang turut mengambil bagian dan tanggung jawab dalam pelaksanaan program tersebut. Ini akan berarti mempercepat berhasilnya tujuan PLH itu. Seorang guru akan mengajarkan pokok bahasan atau sub pokok bahasan program PLH bersamaan waktunya dengan saat ia mengajarkan suatu pokok bahasan atau sub pokok bahasan mata pelajaran yang menjadi tanggung jawabnya, yang ada persamaannya atau ada persesuainnya. Dengan demikian perpaduan hendaknya bersifat wajar, tidak dipaksakan dan tidak sampai memberi mata pelajaran wadah perpaduan. Diharapkan dengan tercapainya tujuan instruksional pokok bahasan atau sub pokok bahasan mata pelajaran induk hendaknya tercapai pula tujuan intruksional pokok bahasan atau sub pokok bahasan PLH yang dipadukan (Pratomo, 2009).

Adapun disiplin ilmu pengetahuan yang ditetapkan sebagai wadah perpaduan yang utama adalah Pendidikan Agama, Pendidikan Pancasila dan Kewarganegaraan, Bahasa Indonesia, Ilmu Pengetahuan Sosial, Ilmu Pengetahuan Alam, dan Pendidikan Jasmani.

Selain menyimak video pembelajaran, penggunaan platform youtube sebagai media pembelajaran dapat menjadi media edukasi untuk anak dimana dalam penggunaannya anak diajarkan cara menggunakan teknologi dengan baik sebagai penunjang untuk belajarnya, namun demikian penggunaan platform youtube juga menimbulkan dampak positif dan negatifnya yaitu pada usia sekolah dasar anak biasanya asyik bermain dengan teman-temannya, namun dengan adanya smartphone yang diberikan bisa membuat anak malas untuk bermain di luar rumah dan memilih untuk bermain smartphone di dalam rumah. Dampak negatif tersebut bisa mengakibatkan komunikasi interpersonal anak kepada teman-temannya menjadi terganggu dan tidak efektif. Namun dari dampak negatif yang terjadi, ada pula dampak positif yang bisa terjadi pada anak saat mengakses Youtube yaitu apabila anak tersebut melakukan apa yang ditontonnya di kehidupannya seharihari secara positif, contoh: anak menonton serial Upin dan Ipin dan tayangan tersebut memberikan ilmu yang baik seperti menolong teman yang 
sedang kesusahan atau membantu orang tuanya di rumah. Hal tersebut bisa memberikan pengaruh positif pada perkembangan kemampuan komunikasi interpersonal anak di lingkungannya dan nantinya bisa membagikan pula ilmu tersebut kepada teman-temannya. Dalam hal konten yang ditonton oleh anak tentunya harus ada peran orangtua juga sebagai langkah controlling tontonan anak sehingga anak tidak menonton hal-hal diluar batas usianya.

\section{KESIMPULAN}

Berdasarkan pengkajian tentang implementasi media video pembelajaran pendidikan lingkungan hidup terintegrasi IPA untuk siswa sekolah dasar pada platform youtube. Salah satu di antaranya ialah dengan menata materi pembelajaran dan proses belajar-mengajar. Dalam menata materi pelajaran dapat dipadukan dalam satu pokok bahasan tanpa memberikan batasan yang nyata dari disiplin ilmunya. Artinya, dalam membicarakan satu pokok bahasan, tidak lagi dibatasi konsep dan prinsip dalam satu bidang studi tertentu dalam satu pokok bahasan secara terpisah-pisah, tetapi konsep dan prinsip dari berbagai bidang yang berkaitan dengan permasalahan dalam pokok bahasan itu. Selain penguatan dalam konsep pembelajaran juga penggunaan media pembelajaran yang bervariatif dapat menjadi solusi untuk meningkatkan kualitas pendidikan lingkungan di Indonesia, media tersebut salah satunya berupa media video pembelajaran yang diunggah melalui platform youtube sehingga dapat diakses kapan, dimanapun dan oleh siapapun. Dengan demikian pemahaman siswa di sekolah dasar terkait pendidikan lingkungan hidup akan lebih utuh dan berkaitan dengan penataan proses pembelajaran, UNESCO mendefinisikan tentang pembelajaran tematik yaitu pengajaran terpadu terdiri atas pendekatanpendekatan konsep dan prinsip pembelajaran disajikan dalam satu paket pembelajaran sehingga tampak adanya satu kesatuan pemikiran ilmiah dan fundamental.

\section{DAFTAR PUSTAKA}

Almahendra, R. (2018). APA ITU BIG DATA?: KULIAH HAK SEGALA BANGSA \#2O. Youtube. https://youtu.be/WVozcDVFl 5 A

Barat, U. T. P. K. (2020). Aplikasi Big Data.

Youtube.

https://youtu.be/Pn-m_aEf-t8

Nilakusmawati, D. P. E. (2019). Big Data: Definisi, Sejarah, Karakteristik, dan Penerapannya. Youtube.

https://youtu.be/kYY_2nhE69w

Nugraha, M. F., Rindayanti, R., \& Nurfitriani, M. (2020). Development of Silent Film (Motion Visual) Media in Social Sciences Subjects Types of Class IV Occupations at SDN Cibeureum. Cendekiawan, 2(1), 13-19. https://doi.org/10.35438/cendekia wan.v2i1.170

Pratiwi, A. S., Lestari, A. T., Hendrawan, B., Nugraha, M. F., Nurfitriani, M., Nurkamilah, M., Mujiarto, Musfiroh, T., Nugraha, F., \& Ridwan, W. H. (2019). Digital Video Based Rampak Kendang Learning Media for Deaf Students. Journal of Physics: Conference Series, 1179(1). https://doi.org/10.1088/17426596/1179/1/o12040

Pratomo, S. (2009). Model 
Pembelajaran Tematik dalam Pendidikan Lingkugnan Hidup (PLH) di Sekolah Dasar. Jurnal Pendidikan Dasar, 11(1), 1-18.

Putra, A., \& Patmaningrum, D. A. (2018). Pengaruh Youtube di Smartphone Terhadap Perkembangan Kemampuan Komunikasi Interpersonal Anak. Jurnal Penelitian Komunikasi, 21(2), 159172.

https://doi.org/10.20422/jpk.v21i2.5 89

Rini, Tangkas, I. M., \& Said, I. (2014). Meningkatkan Hasil Belajar Siswa Melalui Penggunaan Metode Demonstrasi Pada Mata Pelajaran IPA Di Kelas III SDN Inpres Tunggaling. Jurnal Kreatif Tadulako Online, 2(1), 67-81. https://media.neliti.com/media/pu blications/116575-ID-

meningkatkan-hasil-belajar-siswamelalui.pdf

Sudjoko, S. (2014). Perkembangan dan konsep dasar pendidikan Lingkungan Hidup. Pendidikan Lingkungan Hidup, 1-41. http://repository.ut.ac.id/4264/2/P EBI4223-M1.pdf

Suko Pratomo, Asep Saefurokhman, M. N. (2010). Pendidikan Lingkungan untuk Sekolah Dasar (Edisi Kedu). UPI Press.

Surakusumah, W. (2009). Konsep pendidikan lingkungan di sekolah: model uji coba sekolah berwawasan lingkungan. Bandung: Universitas Pendidikan Indonesia. http://file.upi.edu/Direktori/FPMI PA/JUR._PEND._BIOLOGI/1972120 31999031-

WAHYU_SURAKUSUMAH/Konse p_Pendidikan_Lingkungan_Hidup. pdf

Unesco-Unep. (1976). The Belgrade Charter. Connect: UNESCO-UNEP
Environmental

Education 